\title{
TEXTURE INDUCED MAGNETIC ANISOTROPY IN Fe-Nd-B MAGNETS PREPARED VIA RAPID SOLIDIFICATION AND HOT EXTRUSION TECHNIQUES
}

\author{
C. J. YANG
}

Marco Material Inc., 144 Rangeway Road, North Billerica, MA 01862, USA

\begin{abstract}
High performance $\mathrm{Fe}-\mathrm{Nd}-\mathrm{B}$ magnets were prepared by consolidation of rapidly solidified melt spun powder using a hot extrusion technique. The extrusion was carried out with various die openings to control the distribution of stresses and strains influencing the possible development of texture. A strong anisotropy in magnetic properties has been found in the extruded magnets. The highest remanence of $10.6 \mathrm{kG}$ and the maximum energy product of $16.6 \mathrm{MGOe}$ were achieved along the through-thickness direction of the magnet extruded into a rectangular cross section. A (001) [120] texture was found to develop in the plane normal to the through-thickness direction. It is suggested that the enhanced remanent magnetization arises principally from the formation of favorable texture.
\end{abstract}

KEY WORDS Fe-Nd-B, rapid solidification, meltspinning, hot extrusion, magnetic anisotropy, texture.

For a magnet material to have a large energy product, it must have a large remanent induction, $B_{r}$, and it must also have a large coercive force $\left(H_{c i} \& H_{c}\right)$. Very few materials have both large $B_{r}$ and $H_{c}$ values and hence the number of high energy permanent magnet material is very restricted. A large magnetocrystalline anisotropy generally has been regarded as a necessary condition for a high energy product in terms of high $B_{r}$. A large $H_{c}$ is a necessary condition but not a sufficient condition for the high energy. Hence it is necessary for prospective permanent magnet material to have a large $B_{r}$ and simultaneously a large anisotropy. In addition, the material must exhibit strong exchange force to remain magnetic to a high temperature, i.e., to have a high Curie temperature.

There are three basic criteria that have to be met by $\mathrm{Fe}($ or $\mathrm{Co})-\mathrm{R}(\mathrm{R}=$ rare earth) magnets to achieve optimum square-loop behavior in the demagnetization regime and hence high energy products: (1) the material must consist of an assembly of fine particles in order to possess high coercivities, $H_{c i}$ and $H_{c}:(2)$ the particles must exhibit microscopic magnetic anisotropy, i.e., they must have a preferred easy axis of magnetization; and (3) the microscopically anisotropic particles must be capable to be aligned with their easy axes all pointing in the same direction in order to achieve high $B_{r}$. Via the principal of rapid solidification technology, the first criterion can be met in the $\mathrm{Fe}-\mathrm{R}-\mathrm{B}$ alloy systems: while the intrinsic characteristics of the $\mathrm{Fe}-\mathrm{R}-\mathrm{B}$ alloys automatically fulfill the second criterion.

Although promising compositions for permanent magnet alloys have been identified in the $\mathrm{Fe}-\mathrm{R}-\mathrm{B}$ systems prepared as films or ribbons utilizing various 
rapid quenching techniques, ${ }^{1-8}$ there is a need to develop a technology aiming at the fulfillment of the third criterion. Therefore, our recent interests ${ }^{9-12}$ have been focussed to develop a technology for consolidation of melt spun $\mathrm{Fe}-\mathrm{R}-\mathrm{B}$ based filaments of amorphous state. The goal is to achieve the essential requirements for: (1) producing the $\mathrm{Fe}_{14} \mathrm{Nd}_{2} \mathrm{~B}$ phase assembled of ultrafine grains to obtain a high $\mathrm{H}_{c}$; and (2) aligning the $\mathrm{Fe}_{14} \mathrm{Nd}_{2} \mathrm{~B}$ crystals with their $c$-axes (easy magnetization axes) oriented in the same direction (texture) in order to achieve a high $B_{r}$.

\section{TECHNICAL APPROACH}

Background-The materials featuring the largest energy product are comprised chiefly of an equilibrium $\mathrm{Fe}-\mathrm{R}-\mathrm{B}$ intermetallic compound. The overall crystal structure of the compound is tetragonal with lattice constants $a=8.8 \AA$, $c=12.2 \AA$, and the stoichiometry is known as $\mathrm{Fe}_{14} \mathrm{R}_{2} \mathrm{~B} \cdot{ }^{13,14}$ Figure 1 shows the unit cell of $\mathrm{Fe}_{14} \mathrm{Nd}_{2} \mathrm{~B}$ crystal ( $\mathrm{P} 4_{2} / \mathrm{mnm}$ space group). The c/a ratio in the figure is exaggerated to emphasize the puckering of the hexagonal iron nets. The structure is built up of alternating sequence of layers, one of Fe atoms and the other

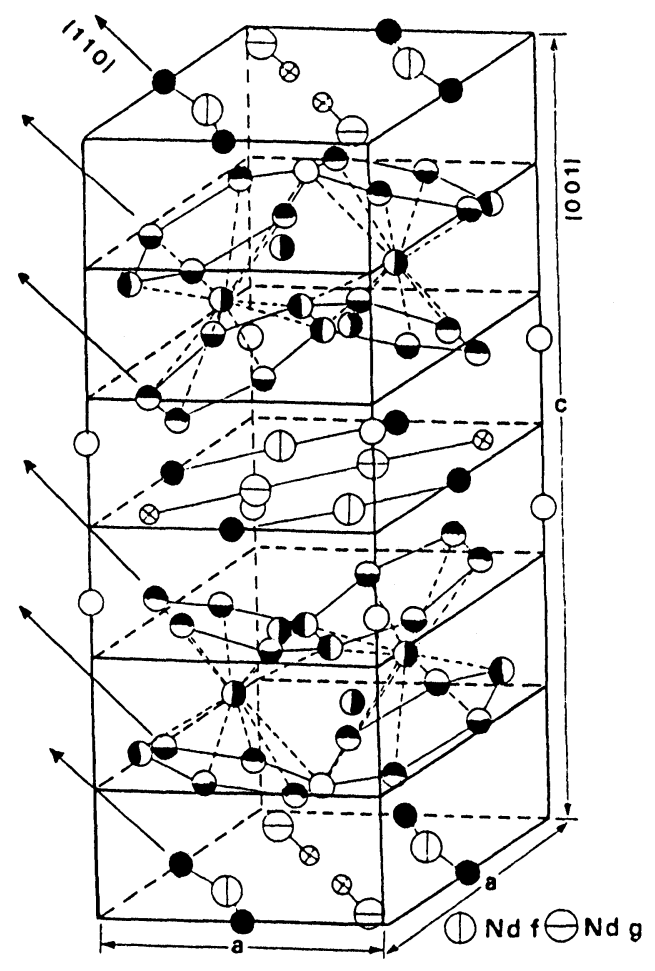

QFec $\bigcirc \mathrm{Fee} \bigcirc \mathrm{Fej}_{1} \bigcirc \mathrm{Fej}_{2} \odot \mathrm{Fek}_{1} \oslash \mathrm{Fek}_{2} \otimes 8 \mathrm{~g}$

Figure 1 Unit cell of the magnetically hard tetragonal $\mathrm{Fe}_{14} \mathrm{Nd}_{2} \mathrm{~B}$ crystal having parameters $a=8.8 \AA$ and $c=12.2 \AA$. 
containing $\mathrm{R}$ and $\mathrm{Fe}$. The Fe layers consist largely of a net work of distorted hexagons. The crystallographically distinguishable species are six for $\mathrm{Fe}$, two for $\mathrm{R}$ and one for $\mathrm{B}$. The nearest neighbor relationships for the six crystallographically distinguishable forms of $\mathrm{Fe}$ vary from $4 \mathrm{R}$ to $12 \mathrm{Fe}$. This variation in coordination number makes the different kinds of $\mathrm{Fe}$ very different magnetically. The tetragonal phase, $\mathrm{Fe}_{14} \mathrm{R}_{2} \mathrm{~B}$, has uniaxial anisotropy which has been confirmed with a single crystal of $\mathrm{Fe}_{14} \mathrm{Nd}_{2} \mathrm{~B} \cdot{ }^{15,16} \mathrm{~A}$ strong uniaxial anisotropy has been found along the $c$-axes for most of $\mathrm{Fe}_{14} \mathrm{R}_{2} \mathrm{~B}$ systems except for the systems with $\mathrm{Sm}$ and Er in which a planar anisotropy has been found. ${ }^{17}$

Hot extrusion-From the analysis of stress and strain boundary conditions during hot extrusion, it appears that a rectangular die opening will create sufficiently anisotropic strain during extrusion across the cross section of the bar in the deformation zone $e^{11,12,18}$ and thereby, will induce texture in the extruded bar. The stresses acting in either longitudinal, transverse, or through-thickness directions induce a geometrical rearrangement of $\mathrm{Fe}_{14} \mathrm{Nd}_{2} \mathrm{~B}$ crystals so that their $c$-axes tend to become parallel to the maximum compressive normal stress. ${ }^{19}$

In Figure 2, the distributions of normal stresses and strains acting during extrusion are illustrated. Three different die openings of circular, square and rectangular cross section were considered. Each circle, square and rectangle in solid line denotes the die opening, and the dashed large circles indicate the initial dimension of billet cross section. Since the required [001] texture is a direct output of strain along the through-thickness (or vertical in square and circle) direction, the strains along through-thickness (or vertical) are evaluated. The arrows in each die opening indicate both magnitude and direction of the normal stress responsible for development of the desirable texture. The coordination of the diagram is such that the extrusion axis, subscript $x x$, is normal to the paper, subscript $y y$ denotes the transverse (or radial for circle) and the $z z$ is for the through-thickness (or vertical) direction, respectively. From the condition of constant volume of material before and after the extrusion, $\varepsilon_{x x}+\varepsilon_{y y}+\varepsilon_{z z}=0$. Therefore, the normal strain acting along the through-thickness (or vertical) direction, $\varepsilon_{z z}$, for each can be derived as follows:

(1) For circular die opening, $\varepsilon_{y y}=\varepsilon_{z z}$. So $\varepsilon_{x x}=-2 \varepsilon_{y y}=-2 \varepsilon_{z z}$; (2) For square opening, $\varepsilon_{y y}=\varepsilon_{z z}$. So $\varepsilon_{x x}=-2 \varepsilon_{y y}=-2 \varepsilon_{z z}$; (3) For rectangular opening,

$$
\varepsilon_{y y}=\frac{d \bar{\varepsilon}}{d \bar{\sigma}}\left(\sigma_{y y}-\frac{1}{2}\left(\sigma_{z z}+\sigma_{x x}\right)\right)=0
$$

where $d \bar{\varepsilon}$ and $d \bar{\sigma}$ is effective strain and effective stress, respectively. The width of the rectangular opening is assumed to be the same as the billet diameter. Since $\sigma_{x x}=0$ so $\sigma_{y y}=1 / 2 \sigma_{z z}$, and $\varepsilon_{x x}=-\varepsilon_{z z}$. Therefore the magnitude of normal strain for a constant extrusion ratio (i.e., constant $\varepsilon_{x x}$ ) is determined as:

$$
\left.\mid \varepsilon_{z z}(\text { rec. })|>| \varepsilon_{z z} \text { (sqr. }\right)|=| \varepsilon_{z z} \text { (cir.) } \mid
$$

The normal strain, $\varepsilon_{z z}$, shows that the rectangular die opening would produce the most prominent $\langle 001\rangle$ texture along through-thickness direction resulting from its high strain.

In plane strain deformation mode the equation for stress equilibrium reduces to a convenient form once hydrostatic stress, $\sigma_{h}$, throughout the plastic zone is determined. ${ }^{18}$ The hydrostatic stress, $\sigma_{h}$, can be defined in the plane plastic 

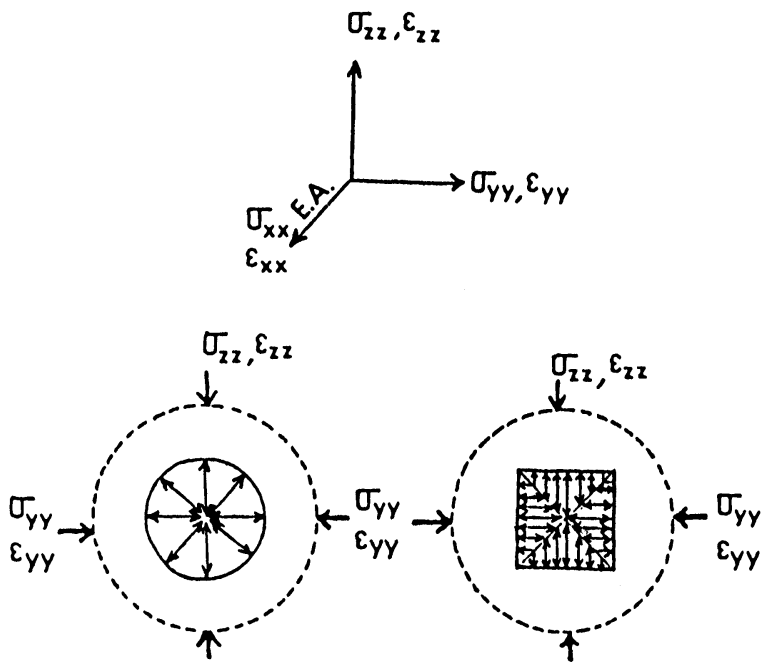

(a)

(b)

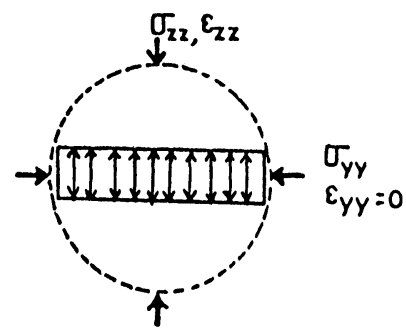

(c)

Figure 2 Schematic drawings illustrating the directions and distributions of stress and strain for a magnet extruded with, (a) circular, (b) square, and (c) rectangular cross section.

strain field such as deformation zone in die inlet section. The plastic zone is assumed to consist of two centered fans of plastic sectors. The bottom half of the plastic sectors is shown in Figure 3(a). A start in working out the stress distribution is made with the assumptions that the dead metal zone, $A B$, must be a slip (or shear) line (no connection with crystallographic), and there is no friction along slip line. Hencky ${ }^{19}$ has established the hydrostatic stress, $\sigma_{h}$, as a function of positions with the aid of slip-line field as follows:

$$
\frac{\delta \sigma_{h}}{\delta \psi}=2 T_{y}, \quad \text { so } \quad \sigma_{h}=K+2 T_{y} \cdot \psi
$$

where $\psi$ is the angle taken as positive counter clockwise, $T_{y}$ is the shear stress of extruding material, and $K$ is a constant for any given line with a value determined 


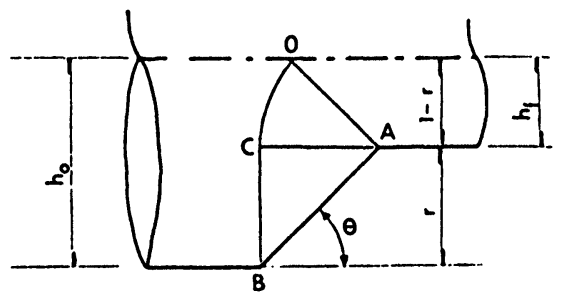

(a)

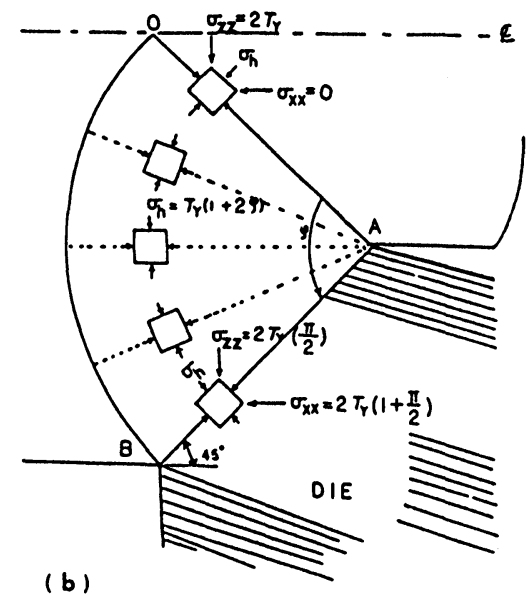

Figure 3 (a) General geometry showing a relationship between die angle and the reduction of extrusion billet; (b) A slip-line field showing the distribution of normal stresses at deformation zone.

by the boundary conditions. Concentrating on sector AOB in Figure 3(b), the state of stress is constant along the slip line AO and all other radial lines, according to the assumption that slip lines are traces of maximum shear strain surfaces and there is no normal strain in the direction of the line. The boundary condition yields the hydrostatic stress, $\sigma_{h}$, which is expressed in terms of the shear stress, $T_{y}$, and angle, $\psi$, taken from the center to the surface of the extruding bar as follows: $\sigma_{h}=T_{y}(1+2 \psi)$.

Then the normal stresses acting in both normal $\left(\sigma_{z z}\right)$ and longitudinal $\left(\sigma_{x x}\right)$ direction can be expressed as a function of angle, $\psi$, along slip line. For instance, since the force across $\mathrm{AO}$ is zero at the center, $\sigma_{x x}=0$ and accordingly $\sigma_{z z}=\sigma_{3}=2 T_{y}$. Again along the $\mathrm{AB}$ line at the surface, $\sigma_{x x}=\sigma_{3}=\sigma_{h}+T_{y}=$ $2(1+\pi / 2)$ and $\sigma_{z z}=\sigma_{1}=\sigma_{h}-T_{y}=2 T_{y}(\pi / 2)$. Between AO and AB the stress state also can be determined at the intermediate states in Figure 3(b). It can be seen that the normal stress acting in $z z$ direction increases $\pi / 2$ times as the position changes from center to the surface. At the same time the normal stress acting in the extrusion direction, $\sigma_{x x}$, increases rapidly from zero at the center to $5.14 T_{y}$ at the surface. Therefore, a possibility is foreseen for a texture having the $c$-axes parallel to the normal stress, $\sigma_{z z}$, to develop in the central region. At the regions close to the surface a distinctive texture may not evolve in unidirection due to the strong stress components acting in the extruding and vertical direction as well. In Figure 4, the extruded magnets with three different cross sections are demonstrated. 


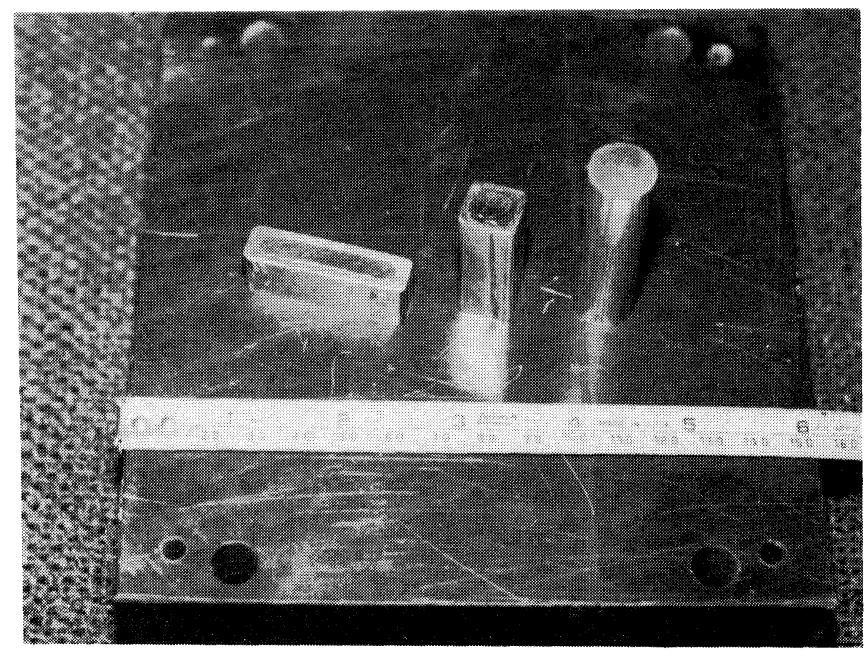

Figure 4 Extruded magnets with three different cross sections.

\section{EXPERIMENTAL}

Three alloys were prepared as starting ingots by arc melting under an argon atmosphere from commercial purity constituents. The compositions were ( $\mathrm{Fe}-$ $\mathrm{Nd}-\mathrm{B})+1 \% \mathrm{HfB}_{2}, \quad(\mathrm{Fe}-\mathrm{Co}-\mathrm{Nd}-\mathrm{B}-\mathrm{Al})+1 \% \mathrm{HfB}_{2}$ and $(\mathrm{Fe}-\mathrm{Co}-\mathrm{Nd}-\mathrm{Dy}-\mathrm{B}-$ $\mathrm{Al})+1 \% \mathrm{HfB}_{2}$, respectively. $\mathrm{HfB}_{2}$ was added to induce fine dispersoids as a mean of grain refinements. ${ }^{11,12}$ The proprietary melt spinning technique was employed to produce rapidly quenched narrow $(10 \mu \mathrm{m}$ thick, $100 \mu \mathrm{m}$ wide) and short amorphous filaments using a substrate speed of $44 \mathrm{~m} / \mathrm{sec}$. In this process, the molten metal is extracted by a knife-edged rotating wheel and converted into filaments solidified at a uniform rate of $10^{6} \cdot \mathrm{C} / \mathrm{sec}$.

$\mathrm{X}$-ray diffraction patterns were obtained from the rapidly solidified melt spun powders using $\mathrm{Cu}-\mathrm{K} \alpha$ radiation with the settings of $45 \mathrm{kV}$ and $33 \mathrm{~mA}$. The method of preparation of extrusion billet has been described elsewhere. ${ }^{11,12}$ The principal magnetic properties were measured using a hysteresigraph recorder $\left(H_{\max }=30 \mathrm{kOe}\right)$ with the sample premagnetized in a pulse field of $60 \mathrm{kOe}$. Magnetic domain patterns were obtained using the polar Kerr effect. Curie temperatures were determined using a vibrating sample magnetometer applying a magnetic field of $2.5 \mathrm{kOe}$. To study the possibility of texture in the extruded magnet, (212) pole figures were plotted using an automated pole figure device interfacing a SIEMENS 42654-178D goniometer. Co-K $\alpha$ radiation was used with the settings of $35 \mathrm{kV}$ and $9 \mathrm{~mA}$. The pole figures were scaled so that analysis may be done on a $20 \mathrm{~mm}$ diameter Wulffnet.

\section{RESULTS AND DISCUSSION}

\section{$X$-Ray Diffraction of Melt Spun Filaments}

Figure 5 shows a SEM micrograph of $\mathrm{Fe}-\mathrm{Nd}-\mathrm{B}$ base filaments spun with a substrate speed of $44 \mathrm{~m} / \mathrm{sec}$. The ribbon thickness below $10 \mu \mathrm{m}$ and width of 


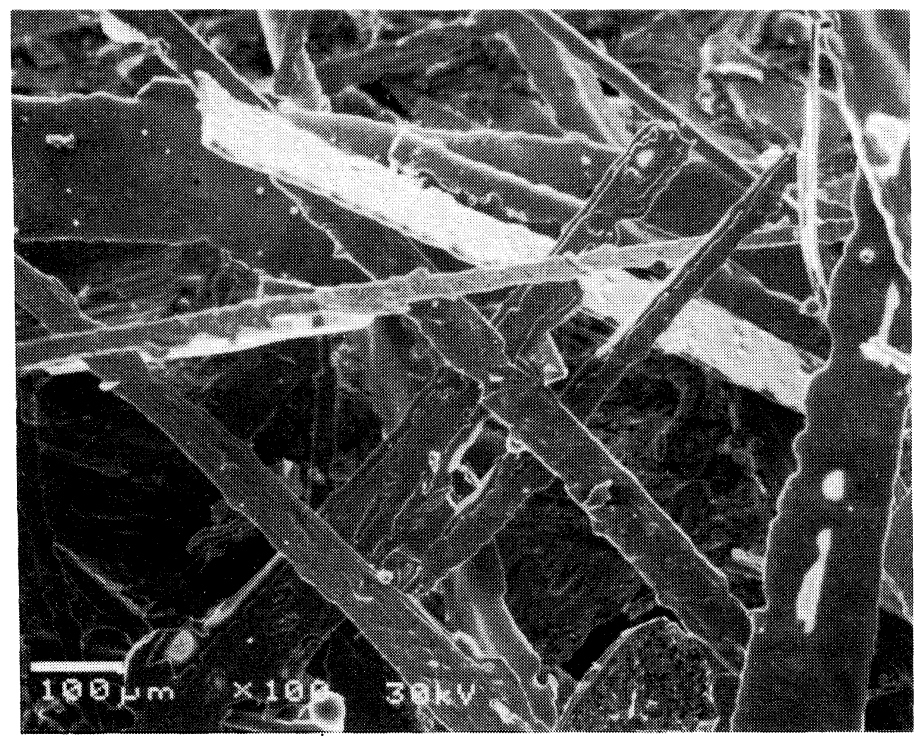

Figure 5 SEM micrograph showing the Fe-Nd-B base filaments spun with a substrate speed of $44 \mathrm{~m} / \mathrm{sec}$.

$100 \mu \mathrm{m}$ indicate the extremely fast quench rate so that the amorphous phase essentially forms. Amorphous phase has been proved to be very effective to make a promising $\mathrm{Fe}-\mathrm{Nd}-\mathrm{B}$ base magnet via the hot consolidation technique. ${ }^{10-12}$ In Figure $6(\mathrm{a})-(\mathrm{c}) \mathrm{X}$-ray diffraction patterns of a sintered $\mathrm{Fe}_{78} \mathrm{Nd}_{16} \mathrm{~B}_{6}$ magnet is compared with those of the melt spun filaments in intermetallic composition $\mathrm{Fe}_{14} \mathrm{Nd}_{2} \mathrm{~B}$ as well as of the spun $\mathrm{Fe}_{78} \mathrm{Nd}_{16} \mathrm{~B}_{6}+1 \% \mathrm{HfB}_{2}$ filaments. The $\mathrm{Fe}_{14} \mathrm{Nd}_{2} \mathrm{~B}$ filaments in Figure 6(b), however, were melt spun with a substrate speed of $22 \mathrm{~m} / \mathrm{sec}$ while the $\mathrm{Fe}_{78} \mathrm{Nd}_{16} \mathrm{~B}_{6}+1 \% \mathrm{HfB}_{2}$ filaments in Figure 6(c) were spun with a speed of $44 \mathrm{~m} / \mathrm{sec}$. Although considerable line broadening is evident in both patterns of $\mathrm{Fe}_{14} \mathrm{Nd}_{2} \mathrm{~B}$ and $\mathrm{Fe}_{78} \mathrm{Nd}_{16} \mathrm{~B}_{6}+1 \% \mathrm{HfB}_{2}$ filaments, there is a one-to-one correspondence with the pattern of a sintered $\mathrm{Fe}_{78} \mathrm{Nd}_{16} \mathrm{~B}_{6}$ magnet. The presence of minority phase, at least Nd-rich phase, was not detected within the limit of x-ray resolution. The discrete peaks above the diffused background of Figure 6(c) is the characteristic of an amorphous plus very fine crystalline microstructure..$^{9,10}$ An investigation of the lattice parameters showing an increased interplanar spacings of as-spun $\mathrm{Fe}_{78} \mathrm{Nd}_{16} \mathrm{~B}_{6}+1 \% \mathrm{HfB}_{2}$ filaments ${ }^{11,12}$ suggested that the extremely fast cooling rate $(44 \mathrm{~m} / \mathrm{sec})$ led to retention of hafnium (Hf) and boron (B) in the amorphous phase or in metastable solid solution phase based on $\mathrm{Fe}_{78} \mathrm{Nd}_{16} \mathrm{~B}_{6}$ stoichiometry.

\section{The Effect of $\mathrm{HfB}_{2}$ on Magnetic Properties}

A significant role of $\mathrm{HfB}_{2}$ dispersoids on the effect of grain refinement is briefly discussed here. When the melt spun filaments supersaturated with $\mathrm{Hf}$ and $\mathrm{B}$ are extruded at $950-1050^{\circ} \mathrm{C}$, the precipitation of equilibrium $\mathrm{HfB}_{2}$ takes place as fine dispersoids. ${ }^{11,12,20}$ This fine dispersion offers great resistance to recrystallization during hot consolidation and post working operation. The $\mathrm{HfB}_{2}$ dispersion 

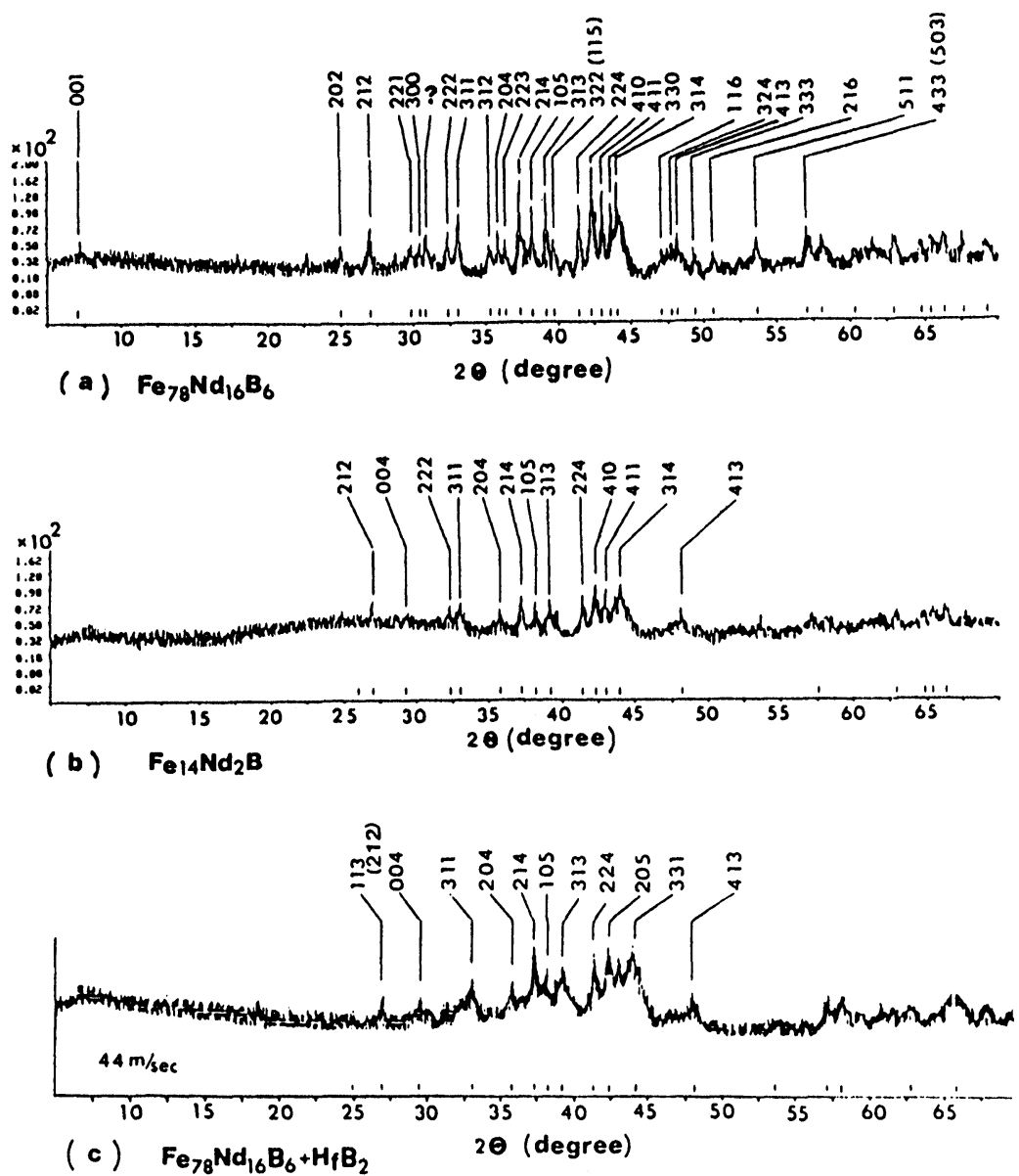

Figure 6 X-ray diffraction pattern of (a) $\mathrm{Fe}_{78} \mathrm{Nd}_{16} \mathrm{~B}$ magnet, (b) $\mathrm{Fe}_{14} \mathrm{Nd}_{2} \mathrm{~B}$ filaments, and (c) $\mathrm{Fe}_{78} \mathrm{Nd}_{16} \mathrm{~B}_{6}+1 \% \mathrm{HfB}_{2}$ filaments, respectively.

induced ultra fine grain size leading to enhanced coercivity has been proved to improve the magnetic properties effectively. ${ }^{11,12}$ Figure 7 shows the typical demagnetization curves of extruded $\mathrm{Fe}_{78} \mathrm{Nd}_{16} \mathrm{~B}_{6}$ magnet containing $\mathrm{HfB}_{2}$ dispersoid (solid line) and the magnet which does not contain $\mathrm{HfB}_{2}$ dispersoid (dashed line). The effect of $\mathrm{HfB}_{2}$ dispersoids is remarkable. Figures 8(a)-(b) show the predominant role of $\mathrm{HfB}_{2}$ dispersion on the grain size of the extruded $\mathrm{Fe}_{78} \mathrm{Nd}_{16} \mathrm{~B}_{6}$ magnet. Employing the dispersion of $\mathrm{HfB}_{2}$, the grain size decreases from average $18 \mu \mathrm{m}$ to $1.5 \mu \mathrm{m}$.

In Table 1 and Table 2, the principal magnetic properties enhanced due to the presence of $\mathrm{HfB}_{2}$ dispersion are summarized for the crystallized powders and for the extruded magnets, respectively. The measurements were made along the transverse direction of the magnet extruded with a square cross section. 
(kG)

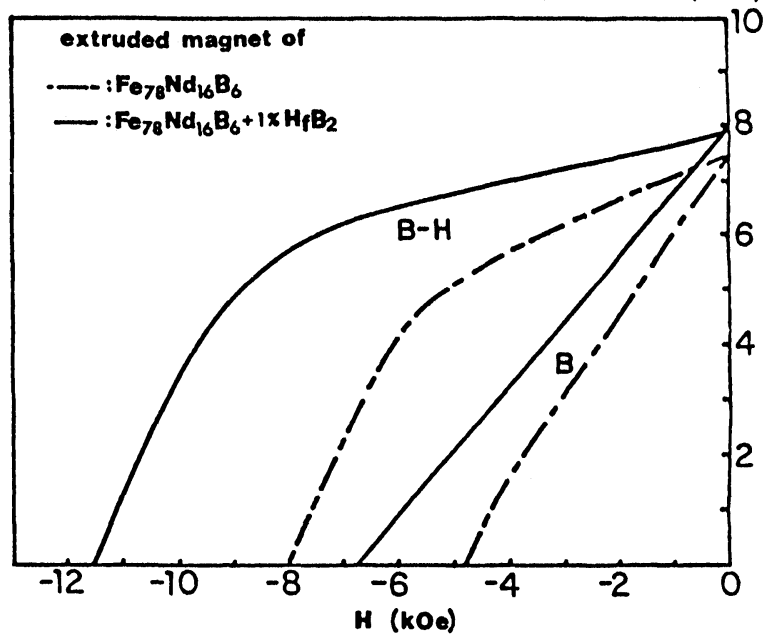

Figure 7 Typical demagnetization curves of the extruded magnet of (a) $\mathrm{Fe}_{78} \mathrm{Nd}_{16} \mathrm{~B}_{6}+1 \% \mathrm{HfB}_{2}$ (solid line) and (b) $\mathrm{Fe}_{78} \mathrm{Nd}_{16} \mathrm{~B}_{6}$ (dashed line), respectively.

\section{Texture and Magnetic Properties}

Figure 9 shows a (212) pole figure of the extruded $\mathrm{Fe}_{78} \mathrm{Nd}_{16} \mathrm{~B}_{6}+1 \% \mathrm{HfB}_{2}$ magnet with a square cross section. The denoted intensity is times random intensity. The coordination of the pole figure is such that the extrusion axis (EA) is normal to the plane of the figure and the two transverse directions are indicated as $\mathrm{TD}_{1}$ and $\mathrm{TD}_{2}$. It can be seen that the maximum intensities of $\{212\}$ poles are localized at the positions of $\{212\}$ in the (110) standard stereographic projection, the solid triangles in the figure. When the above analysis is correct, the extrusion axis corresponds to [110] which is identical to the previous observation. ${ }^{11,12}$ And then one of the transverse directions $\left(\mathrm{TD}_{1}\right)$ is determined to deviate $6^{\circ}$ from [001]. $\mathrm{TD}_{2}$ is then $6^{\circ}$ away from [110].

The corresponding demagnetization curves of the same magnet used for the plotting of pole figure, Figure 9, are shown in Figure 10. The dashed line corresponds to the measurement made along the extrusion axis and the solid line to the transverse direction, $\mathrm{TD}_{1}$. These typical demagnetization curves suggest that the easy magnetization axis is oriented close to the transverse direction $\left(\mathrm{TD}_{1}\right)$ along which the better squareness and a high remanent magnetization $\left(\mathrm{B}_{\mathrm{r}}\right)$ leading to a high energy product were obtained.

Figure 11 shows a (212) pole figure of the $\mathrm{Fe}_{78} \mathrm{Nd}_{16} \mathrm{~B}_{6}+1 \% \mathrm{HfB}_{2}$ magnet extruded with a rectangular cross section. The pole intensities were collected from the plane normal to the through-thickness direction. TT corresponds to the through-thickness direction, the longitudinal direction (LD) indicates the extrusion axis (EA), and TD is for the transverse direction, respectively. This pole figure is characterized as showing a sign of preferred orientation. The maximum $\{212\}$ pole intensities can be seen to be localized at $\{212\}$ poles in the (001) standard stereographic projection. The extrusion axis is observed to deviate $18^{\circ}$ 


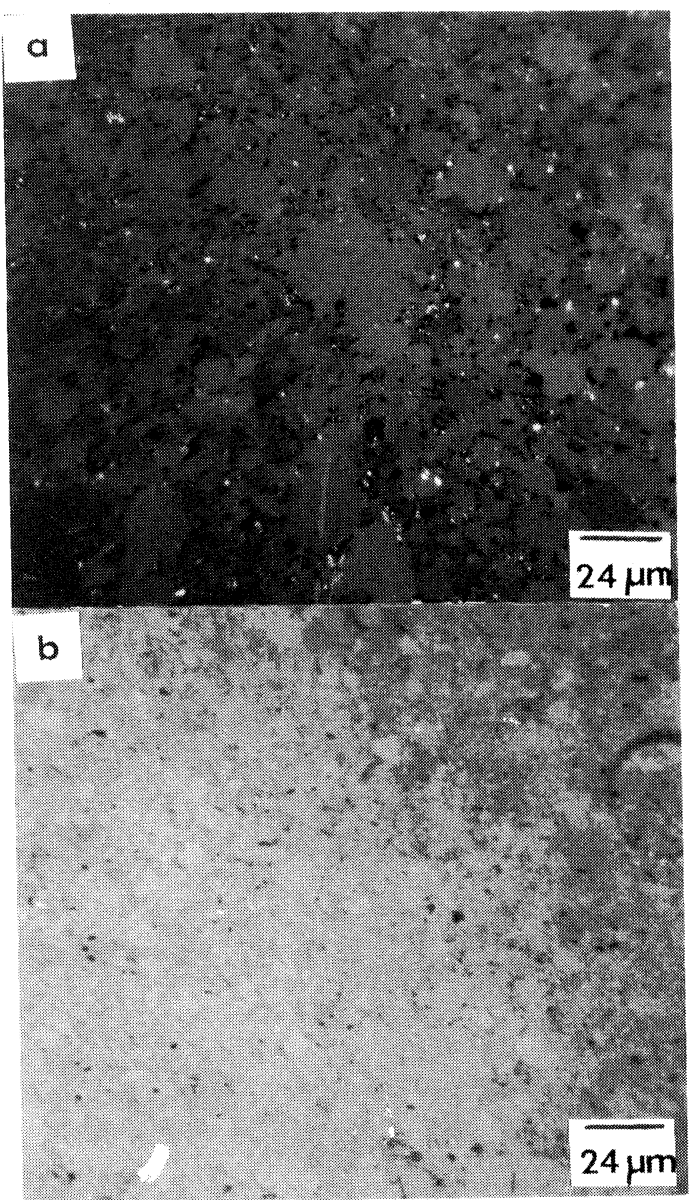

Figure 8 Optical micrograph showing the grain aspects of (a) $\mathrm{Fe}_{78} \mathrm{Nd}_{16} \mathrm{~B}_{6}$, and (b) $\mathrm{Fe}_{78} \mathrm{Nd}_{16} \mathrm{~B}_{6}+$ $1 \% \mathrm{HfB}_{2}$ magnet, respectively.

Table 1 Principal magnetic properties of aligned green compacts made from crystallized powders.

\begin{tabular}{|c|c|c|c|c|c|}
\hline Properties & $\begin{array}{l}B_{r} \\
(k G)\end{array}$ & $\begin{array}{l}H_{c i} \\
(k O e)\end{array}$ & $\begin{array}{l}H_{c} \\
(k O e)\end{array}$ & $\begin{array}{l}(B-H) \\
(M G O e)\end{array}$ & $\begin{array}{l}T_{c} \\
(C)\end{array}$ \\
\hline $\mathrm{Fe}_{78} \mathrm{Nd}_{16} \mathrm{~B}_{6}$ & 4.5 & 10.8 & 3.0 & 3.4 & 320 \\
\hline $\mathrm{Fe}_{78} \mathrm{Nd}_{15} \mathrm{~B}_{7}+1 \% \mathrm{HfB}_{2}$ & 6.6 & 15.6 & 3.2 & 5.3 & 320 \\
\hline $\mathrm{Fe}_{65} \mathrm{Co}_{10} \mathrm{Nd}_{15} \mathrm{~B}_{7} \mathrm{Al}_{3}$ & 4.9 & 7.6 & 3.0 & 3.8 & 430 \\
\hline $\mathrm{Fe}_{64} \mathrm{Co}_{15} \mathrm{Nd}_{13} \mathrm{~B}_{6} \mathrm{Al}_{2}+1 \% \mathrm{HfB}_{2}$ & 6.6 & 13.8 & 3.2 & 5.3 & 460 \\
\hline $\begin{array}{l}\mathrm{Fe}_{68} \mathrm{Co}_{10} \mathrm{Nd}_{12} \mathrm{Dy}_{2} \mathrm{~B}_{6} \mathrm{Al}_{2} \\
+1 \% \mathrm{HfB}_{2}\end{array}$ & 5.3 & 21.5 & 2.6 & 3.4 & 400 \\
\hline
\end{tabular}


Table 2 The principal magnetic properties of the extruded magnets. Measurements were made along the transverse direction in the perpendicular direction with respect to the extrusion axis.

\begin{tabular}{lcllcl}
\hline Alloy & $\begin{array}{l}\mathrm{Hci} \\
(k O e)\end{array}$ & $\begin{array}{l}\mathrm{Hc} \\
(k O e)\end{array}$ & $\begin{array}{l}\mathrm{Br} \\
(k O e)\end{array}$ & $\begin{array}{l}(\mathrm{B} \cdot \mathrm{H})_{\max } \\
(\mathrm{MGOe})\end{array}$ & $\begin{array}{l}\text { Curie } \\
\text { temp. } \\
(C)\end{array}$ \\
\hline $\mathrm{Fe}_{78} \mathrm{Nd}_{16} \mathrm{~B}_{6}$ & 8.0 & 4.8 & 7.5 & 9.4 & 320 \\
$\mathrm{Fe}_{78} \mathrm{Nd}_{16} \mathrm{~B}_{6}+1 \% \mathrm{HfB}_{2}$ & 11.6 & 6.8 & 8.0 & 15.8 & \\
$\mathrm{Fe}_{78} \mathrm{Nd}_{16} \mathrm{~B}_{6}+1.5 \% \mathrm{TiB}_{2}$ & 7.5 & 4.5 & 7.2 & 8.6 & - \\
\hline
\end{tabular}

from [110] and is determined as [120]. When the fact is taken into account that the transverse direction in the square bar magnet is only $6^{\circ}$ away from $\langle 110\rangle$, the observation of (001) [120] texture is an expectable result.

The typical demagnetization curve of the magnet extruded with amorphous melt spun powders of $\mathrm{Fe}_{78} \mathrm{Nd}_{16} \mathrm{~B}_{6}+1 \% \mathrm{HfB}_{2}$ is shown in Figure 12. Anisotropy in magnetic properties is prominent in this rectangular bar magnet. The remanent magnetization, $10.6 \mathrm{kG}$, observed along the through-thickness direction is con-

(212) POLE FIGURE

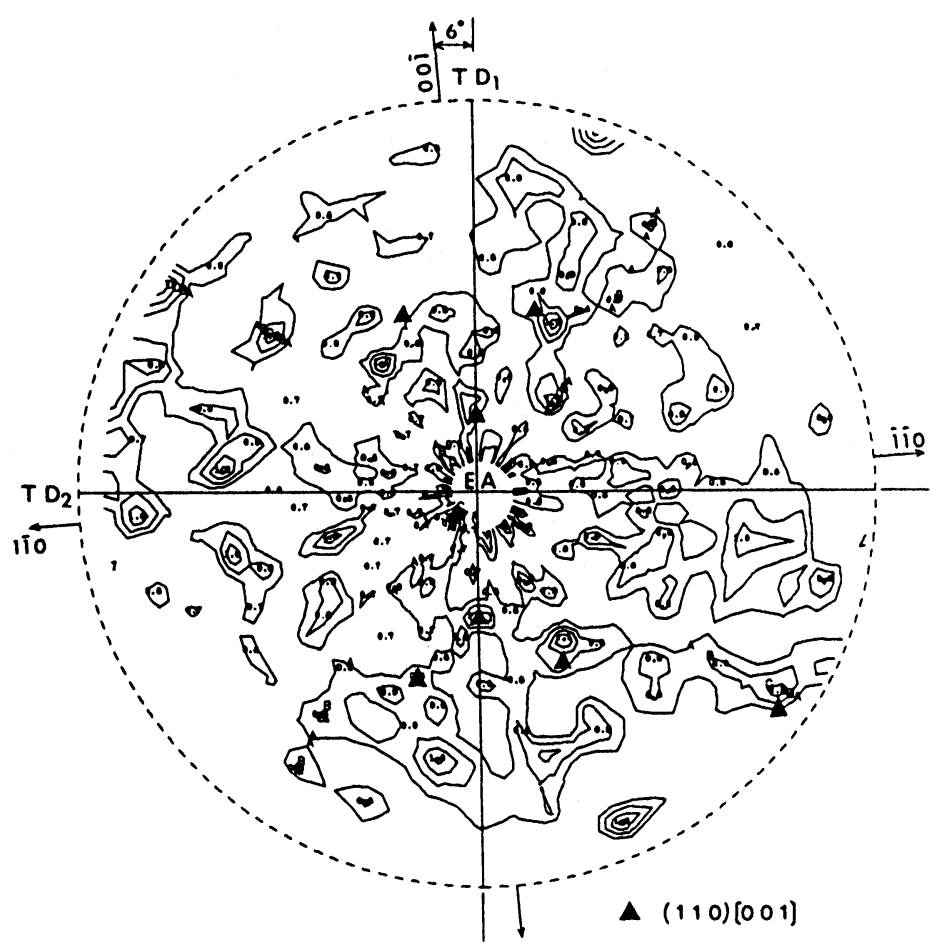

Figure 9 (212) pole figure determined from the plane normal to the extrusion axis of $\mathrm{Fe}_{78} \mathrm{Nd}_{16} \mathrm{~B}_{6}+$ $1 \% \mathrm{HfB}_{2}$ magnet with a square cross section. 


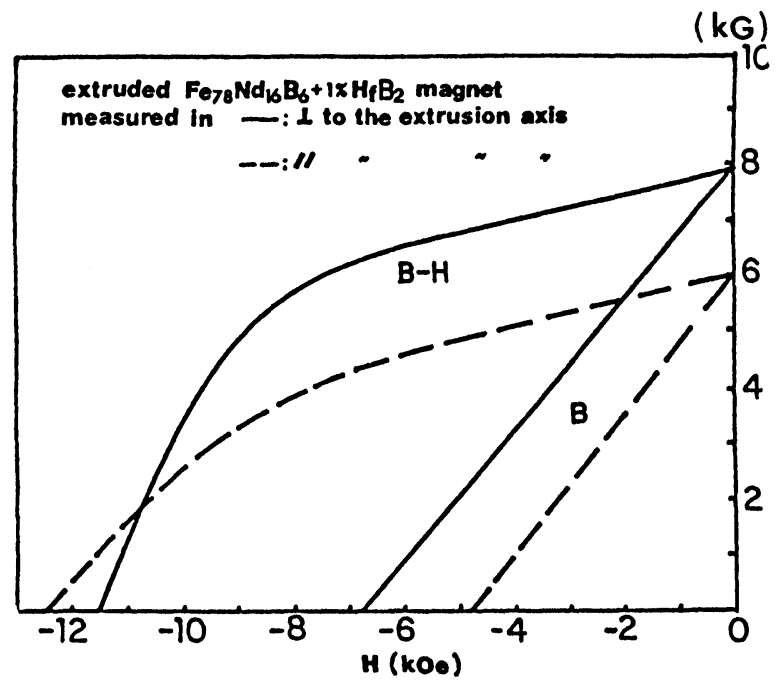

Figure 10 Typical demagnetization curves of the extruded $\mathrm{Fe}_{78} \mathrm{Nd}_{16} \mathrm{~B}_{6}+1 \% \mathrm{HfB}_{2}$ magnet with a square cross section.

sidered as a promising value when the fact is taken into account that this magnet was consolidated directly from the isotropic melt spun amorphous powders. The remanences observed along the transverse and longitudinal directions can be seen to decrease $15 \%$ and $26 \%$, respectively, with respect to that of through-thickness direction. It can be seen in Figure 12 that the energy product is a function of remanent magnetization in which the demagnetization behavior of high remanence shows a good squareness along the curves. As pointed out, the high remanence of this alloy essentially has led to a high energy product (16.6 MGOe) while the coercivities remain nearly constant ranging over $10 \mathrm{kOe}$ in all orientations of the extruded magnet.

Considering the tetragonal $\mathrm{Fe}_{14} \mathrm{Nd}_{2} \mathrm{~B}$ crystal in Figure 1 one can make an interesting interpretation regarding the superiority in magnetic properties along TD to LD. At each top, mid and bottom plane of the tetragonal crystal, two pairs of $\mathrm{Fe}(\mathrm{c})-\mathrm{Nd}(\mathrm{f})$ bonds can be seen to develop along [110]. Of course a pair of $\mathrm{Nd}(\mathrm{g})-\mathrm{B}(\mathrm{g})$ bond also can be seen along the same orientation. But the $\mathrm{Nd}(\mathrm{g})-\mathrm{B}(\mathrm{g})$ bond does not contribute to the magnetic properties while $\mathrm{Fe}(\mathrm{c})-$ $\mathrm{Nd}(\mathrm{f})$ bond has been known to play a significant role in this structure. ${ }^{17}$ Each $\mathrm{Fe}(\mathrm{j} 1)-\mathrm{Fe}(\mathrm{j} 1), \mathrm{Fe}(\mathrm{j} 2)-\mathrm{Fe}(\mathrm{j} 2), \mathrm{Fe}(\mathrm{k} 1)-\mathrm{Fe}(\mathrm{k} 1)$, and $\mathrm{Fe}(\mathrm{k} 2)-\mathrm{Fe}(\mathrm{k} 2)$ bond in basal planes of twin hexagonal structure found at the half top and half bottom of the tetragonal crystal also can be seen to align in [110] direction. Along $\langle 120\rangle$, however, neither $\mathrm{Fe}-\mathrm{Fe}$ nor $\mathrm{Fe}-\mathrm{Nd}$ bond can be found.

Figure 13 demonstrates the demagnetization curves of the (Fe-Nd-B) + $1 \% \mathrm{HfB}_{2}$ magnets extruded with a rectangular and square cross section, respectively, and of the (Fe-Co-Nd-B) magnet extruded with a circular cross section. Each demagnetization curve was measured along the direction from which the maximum energy product in terms of the maximum remanences has been obtained. It is clearly shown that the magnet of rectangular cross section produces 
( $\left.\begin{array}{lll}2 & 1 & 2\end{array}\right)$ POLE FIGURE

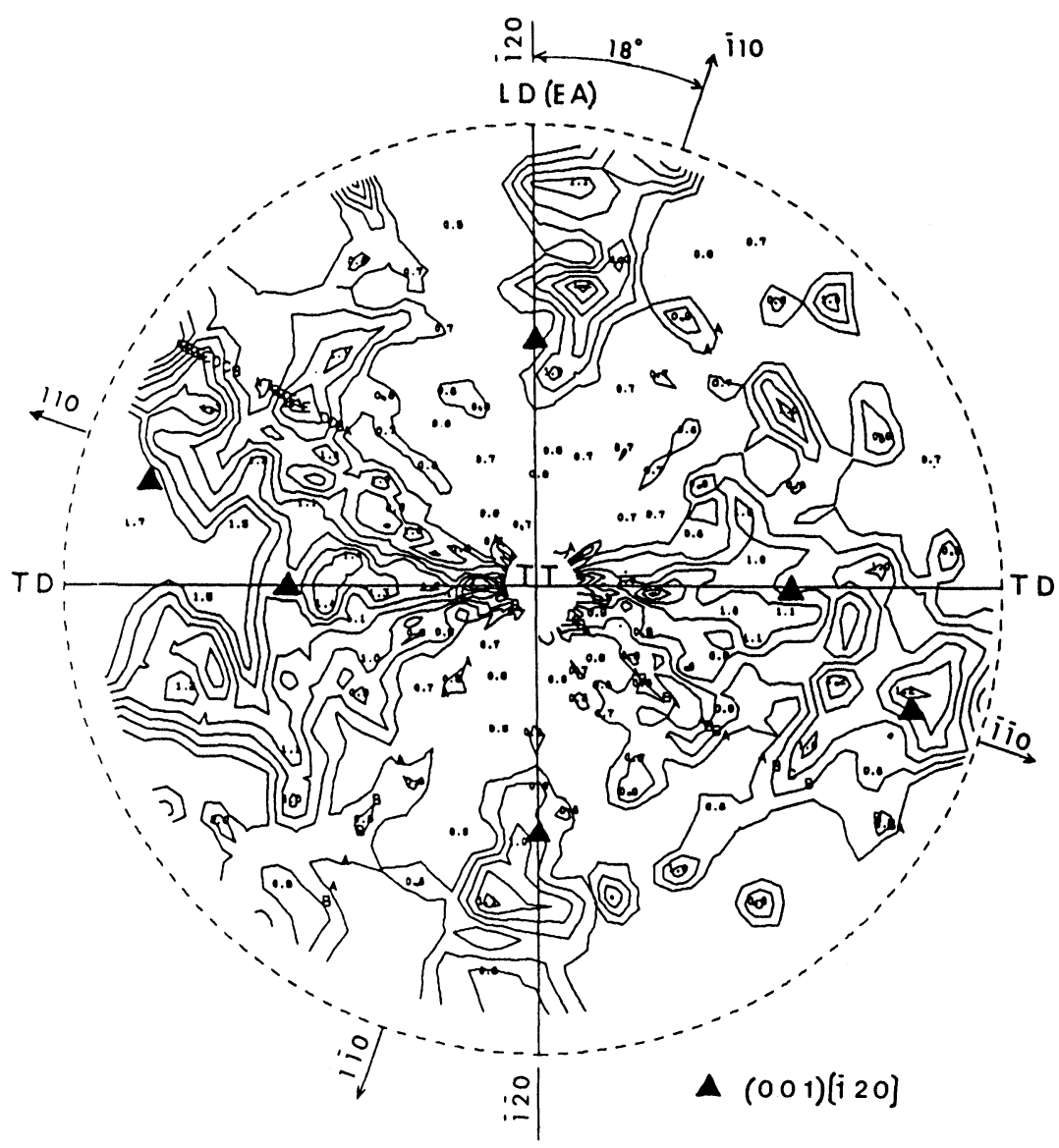

Figure 11 (212) pole figure determined from the plane normal to the through-thickness direction of $\mathrm{Fe}_{78} \mathrm{Nd}_{16} \mathrm{~B}_{6}+1 \% \mathrm{HfB}_{2}$ magnet with a rectangular cross section.

the highest remanence while the lower remanences $\left(B_{r}=8.0 \mathrm{kG}\right)$ are obtained from the other magnets. As predicted at the beginning, the normal strain (estimated strain is $\varepsilon_{z z} \times 2.48$ ) along the through-thickness direction effectively influenced the development of texture. This rectangular bar magnet was extruded at $1080^{\circ} \mathrm{C}$ while the other two magnets were extruded at $1000^{\circ} \mathrm{C}$. Therefore a considerable grain coarsening might have taken place in the rectangular bar magnet which showed a deterioration in coercivities $\left(\mathrm{H}_{\mathrm{c}}\right.$ and $\left.\mathrm{H}_{\mathrm{ci}}\right)$ as shown in Figure13. Table 3 summarizes the principal magnetic properties of the rectangular bar magnets of three different compositions.

Polar Kerr effect showing the grain aspects and magnetic domain patterns of an 


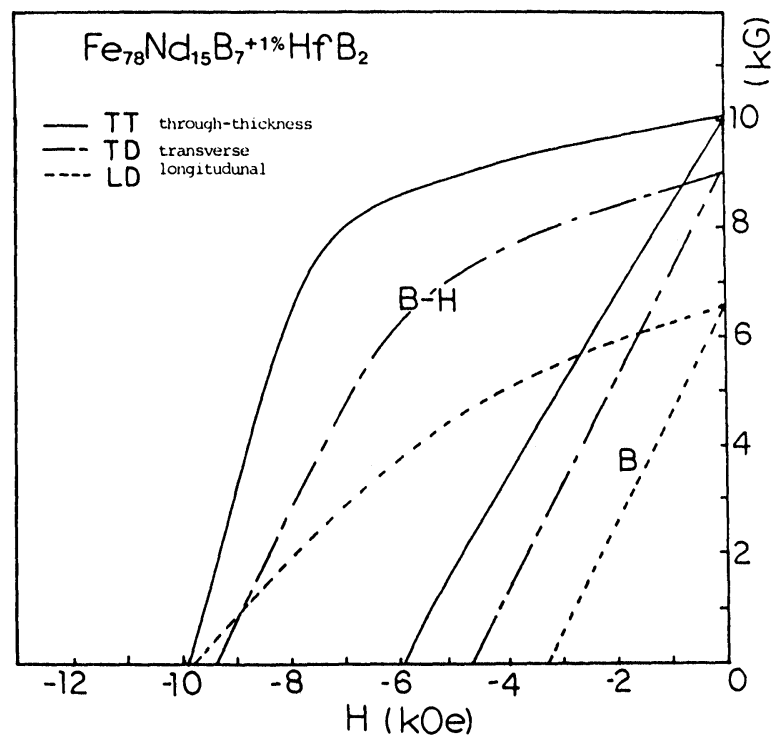

Figure 12 Typical demagnetization curves of the extruded $\mathrm{Fe}_{78} \mathrm{Nd}_{16} \mathrm{~B}_{6}+1 \% \mathrm{HfB}_{2}$ magnet with a rectangular cross section.

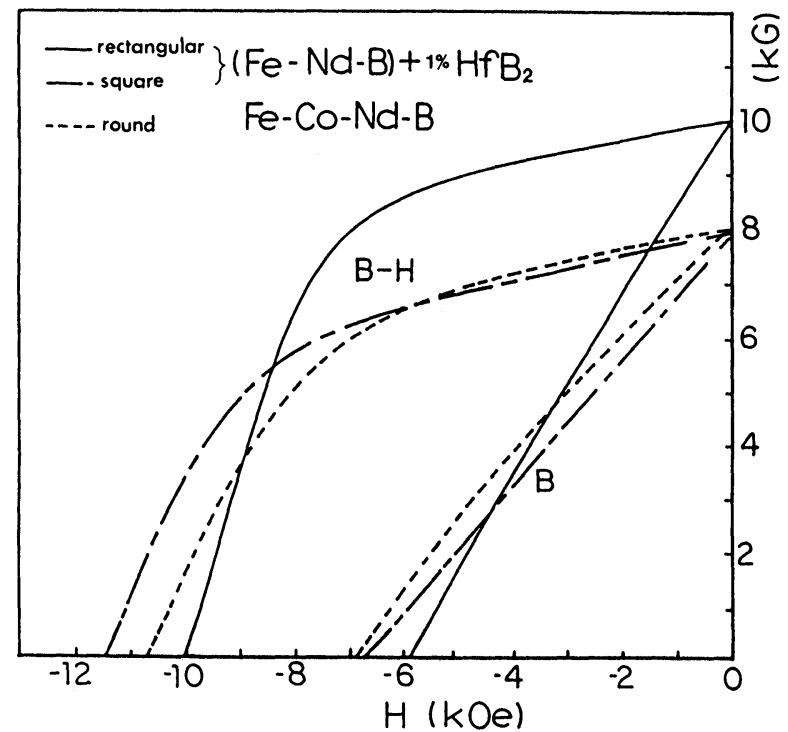

Figure 13 Typical demagnetization curves demonstrating the effect of cross section on the remanent magnetization of $\mathrm{Fe}-\mathrm{Nd}-\mathrm{B}$ magnet. 
Table 3 Principal magnetic properties of the magnet extruded with melt spun powders.

\begin{tabular}{|c|c|c|c|c|}
\hline Alloy/Orientation & $\begin{array}{l}B r \\
(k G)\end{array}$ & $\begin{array}{l}\mathrm{Hci} \\
(k O e)\end{array}$ & $\begin{array}{l}H c \\
(k O e)\end{array}$ & $\begin{array}{l}(B-H) \\
(M G O e)\end{array}$ \\
\hline \multicolumn{5}{|l|}{$\mathrm{Fe}_{78} \mathrm{Nd}_{15} \mathrm{~B} 7+1 \% \mathrm{HfB}_{2}$} \\
\hline transverse & 9.0 & 9.4 & 4.6 & 10.7 \\
\hline longitudinal & 6.7 & 9.7 & 3.3 & 5.5 \\
\hline \multicolumn{5}{|l|}{$\mathrm{Fe}_{64} \mathrm{Co}_{15} \mathrm{Nd}_{13} \mathrm{~B}_{6} \mathrm{Al}_{2}+1 \% \mathrm{HfB}_{2}$} \\
\hline through-thickness & 9.0 & 7.4 & 4.7 & 12.0 \\
\hline transverse & 6.8 & 7.0 & 3.8 & 6.5 \\
\hline longitudinal & 6.0 & 8.0 & 3.2 & 4.7 \\
\hline \multicolumn{5}{|l|}{$\mathrm{Fe}_{68} \mathrm{Co}_{10} \mathrm{Nd}_{12} \mathrm{Dy}_{2} \mathrm{~B}_{6} \mathrm{Al}_{2}+1 \% \mathrm{HfB}_{2}$} \\
\hline through-thickness & 8.6 & 18.8 & 5.1 & 10.1 \\
\hline transverse & 7.9 & 20.4 & 4.7 & 9.4 \\
\hline
\end{tabular}
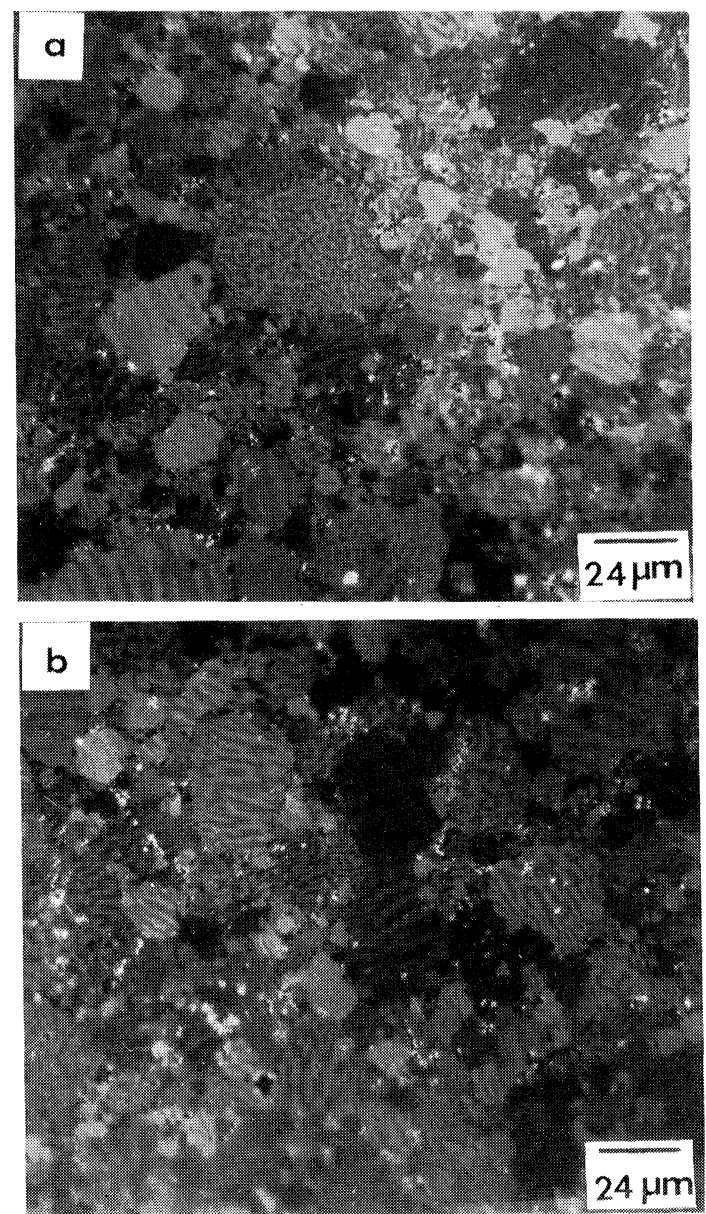

Figure 14 Polar Kerr effect showing the grain aspect and magnetic domain patterns of an extruded $\mathrm{Fe}_{62} \mathrm{Co}_{15} \mathrm{Nd}_{15} \mathrm{~B}_{8}$ magnet. (a) Polar patterns obtained from the plane normal to the transverse direction, and (b) plane from the cross section. 
extruded $\mathrm{Fe}_{62} \mathrm{Co}_{15} \mathrm{Nd}_{15} \mathrm{~B}_{8}$ magnet with square cross section is shown in Figure 14. Figure 14(a) was taken from the longitudinal section and Figure 14(b) from the cross section. A number of grains having pole faced domains in Figure 14(a) indicate that a large portion of grains are aligned with their $c$-axes perpendicular to the extrusion axis. In Figure 14(b), however, many grains showing $180^{\circ}$ domains suggest that the easy magnetization would lie in the plane of the picture.

\section{CONCLUSION}

Control of the state of $\mathrm{HfB}_{2}$ dispersion as well as development of texture was shown to lead to fabrication of magnets with excellent properties via the route of melt spinning followed by hot extrusion. The extrusion was carried out with various die openings to control the distribution of stresses and strains influencing the development of possible texture. A strong anisotropy in magnetic properties has been found in the extruded magnets. The highest remanence of $10.6 \mathrm{kG}$ and the maximum energy product of $16.6 \mathrm{MGOe}$ were achieved along the throughthickness direction of the magnet extruded with a rectangular cross section. A (001) [120] texture was found to develop in the plane normal to the throughthickness direction. It is concluded that the enhanced remanent magnetization arises principally from the formation of favorable texture.

\section{References}

1. Clark, A. E. (1973). Appl. Phys. Lett. 23, 642-644.

2. Croat, J. J. (1980). Appl. Phys. Lett. 37, 1096-1098.

3. Croat, J. J. (1981). Appl. Phys. Lett. 39, 357-359.

4. Koon, N. C. and Das, B. N. (1981). Appl. Phys. Lett. 39, 840-842.

5. Croat, J. J. (1982). J. Appl. Phys. 53, 3161-3164.

6. Hadjipanyis, G. C., Hazelton, R. C. and Lawless, K. R. (1984). J. Appl. Phys. 55, 2073-2075.

7. Croat, J. J., Herbst, J. F., Lee, R. W. and Pinkerton, F. E. GMR-4492, General Motors research Laboratories, October 12, 1983, Warren MI.

8. Koon, N. C. and Das, B. N. (1984). J. Appl. Phys. 55, 2063-2065.

9. Yang, C. J., Ray, R. and O'Handley, R. C. J. Mat. Sci. \& Eng. 89, March (1988).

10. Yang, C. J. and O'Handley, R. C. J. Mat. Sci. \& Eng. 89, April (1988).

11. Yang, C. J. and Ray, R. J. Appl. Phys. 63, 3525-3527 (1988).

12. Yang, C. J. and Ray, R. in Peter Lee (ed.), Proc. 2nd. International Conference on Rapidly Solidified Materials, ASM International, San Diego, Calf., March 7-9, 19-27 (1988).

13. Herbst, J. F., Croat, J. J., Pinkerton, F. E. and Yelon, W. B. (1984). Phys. Rev. B29, 4176-4178.

14. Givord, D., Li, H. S. and Moreau, J. M. (1984). Solid State Commun. 50, 497-501.

15. Koon, N. C., Das, B. N. and Rubinstein, M. (1985). J. Appl. Phys. 57(8), 4091-4093.

16. Sagawa, M., Fujimura, S., Yamamota, H. and Hirosawa, S. (1985). J. Appl. Phys. 57(8), 4094-4096.

17. Wallace, W. E. (1986). Solid State Chemistry 16, 127-147.

18. Backofen, W. A. Deformation Processing, p. 119, Addison-Wesley, Reading, MA (1972).

19. Mishra, R. K. (1987). J. Appl. Phys. 62, 967-980.

20. Yang, C. J. to be published in J. Appl. Phys. November (1988). 